\title{
Laser-Induced Damage and Recovery of Plasmonically Targeted Human Endothelial Cells
}

\author{
Dorota Bartczak, ${ }^{\dagger}$ Otto L. Muskens, ${ }^{\dagger}$ Timothy M. Millar, ${ }^{\ddagger}$ Tilman Sanchez-Elsner, ${ }^{\dagger}$ and \\ Antonios G. Kanaras, ${ }^{*}$ \\ ${ }^{\dagger}$ School of Physics and Astronomy and ${ }^{\ddagger}$ School of Medicine, University of Southampton, Southampton, SO17 1BJ, U.K. \\ Supporting Information
}

ABSTRACT: Laser-induced techniques that employ the surface plasmon resonances of nanoparticles have recently been introduced as an effective therapeutic tool for destroying tumor cells. Here, we adopt a low-intensity laser-induced technique to manipulate the damage and repair of a vital category of noncancerous cells, human endothelial cells. Endothelial cells construct the interior of blood vessels and play a pivotal role in angiogenesis. The degree of damage and repair of the cells is shown to be influenced by laser illumination in the presence of gold nanoparticles of different morphologies, which either

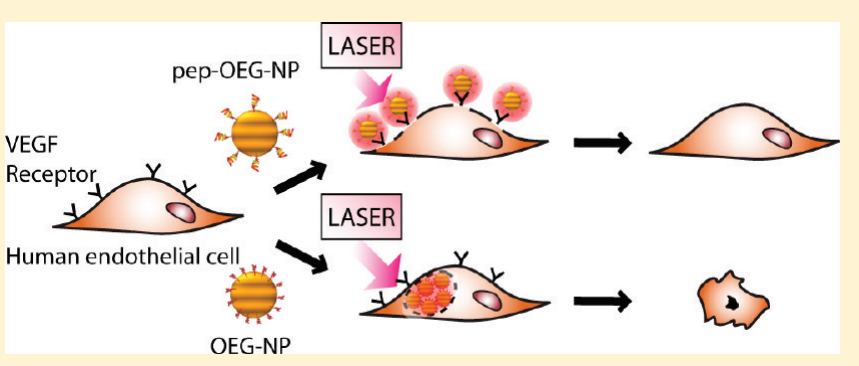
target the cellular membrane or are endocytosed. A pronounced influence of the plasmonic nanoparticle laser treatment on the expression of critical angiogenic genes is shown. Our results show that plasmon-mediated mild laser treatment, combined with specific targeting of cellular membranes, enables new routes for controlling cell permeability and gene regulation in endothelial cells.

KEYWORDS: Gold nanoparticles, endothelium, peptides, hyperthermia, laser treatment, plasmon

$\mathrm{N}$ anomedicine, the application of nanotechnology to the diagnostics and treatment of diseases, is seeing enormous development. This is being fueled by the advances in laserinduced techniques as well as by the synthesis of sophisticated nanoparticles, which are functional and biologically robust. ${ }^{1}$ For example, plasmonic nanoparticles are increasingly employed as agents in cancer theranostics because of their favorable optoelectronic properties, provided by the tunable near-infrared absorption band, and their ability to efficiently convert light to heat. Several research groups reported the use of engineered gold nanoparticles as biomarkers to detect cells in vitro and In Vivo ${ }^{2}$ and as agents to selectively destroy tumors using the method of destructive hyperthermia. ${ }^{3}$ Currently, functional nanoparticles are being tested in clinical trials to explore their potential for use in human therapy.

Apart from its potential for destroying cancer cells, nanoparticle-laser-induced heat delivery has been successfully employed for releasing small molecules such as drugs ${ }^{4}$ and labeled DNA, ${ }^{5}$ and for enhancing the toxicity of conventional chemotherapeutics. ${ }^{6}$ Although most work on laser-induced nanoparticle cell treatment report a minimal energy threshold required for achieving cell mortality, very little effort has been made to explore the window of opportunity of using laser treatment as a direct, mild tool for manipulating damage and repair of biological cells. A major reason of the damage caused in cells during laser treatment is attributed to thermal effects. ${ }^{7}$ For example, in single-particle studies it was found that irradiation of nanoparticles using a continuous wave laser locally melts a lipid membrane, ${ }^{8}$ while illumination using a high-power pulsed laser showed disintegration of the cell membrane. ${ }^{3 g}$ However, the explanation for the cell damage response induced by nanoparticles is nontrivial due to its dependence on nanoscale physicochemical mechanisms around a single nanoparticle. Expanding the opportunities for applications of laser treatment in biology, Volk and co-workers showed that low laser irradiation of cancer cells containing endosomal gold nanoparticles could generate free radicals leading to controlled endosome rupture and nanoparticle escape into the cytosol, without affecting the cell's viability. ${ }^{9}$

Here, we explore a window of laser-induced nanoparticle treatment, occurring at power densities of $10-24 \mathrm{~W} / \mathrm{cm}^{2}$, i.e. below the threshold of most destructive studies, to achieve nondestructive mild forms of laser-induced treatment. In comparison to other studies involving low laser power (i.e., drug delivery), we use targeted nanoparticles to gain control over the permeability of the cellular membrane as well as the expression of genes.

Our investigation focuses on an important type of noncancerous cells, the endothelial. Endothelial cells are a specialized type of cell, which forms the inner layer of blood vessels and plays a pivotal role in the processes of new blood vessel formation (angiogenesis), inflammation blood pressure, and coagulation. We employed particles, which were functionalized either with peptides that target specific cell surface receptors or without peptides to allow them to be endocytosed. To assess the

$\begin{array}{ll}\text { Received: } & \text { December 28, } 2010 \\ \text { Revised: } & \text { February 8, 2011 } \\ \text { Published: } & \text { February 15, } 2011\end{array}$

Received: December 28, 2010

Published: February 15, 2011 


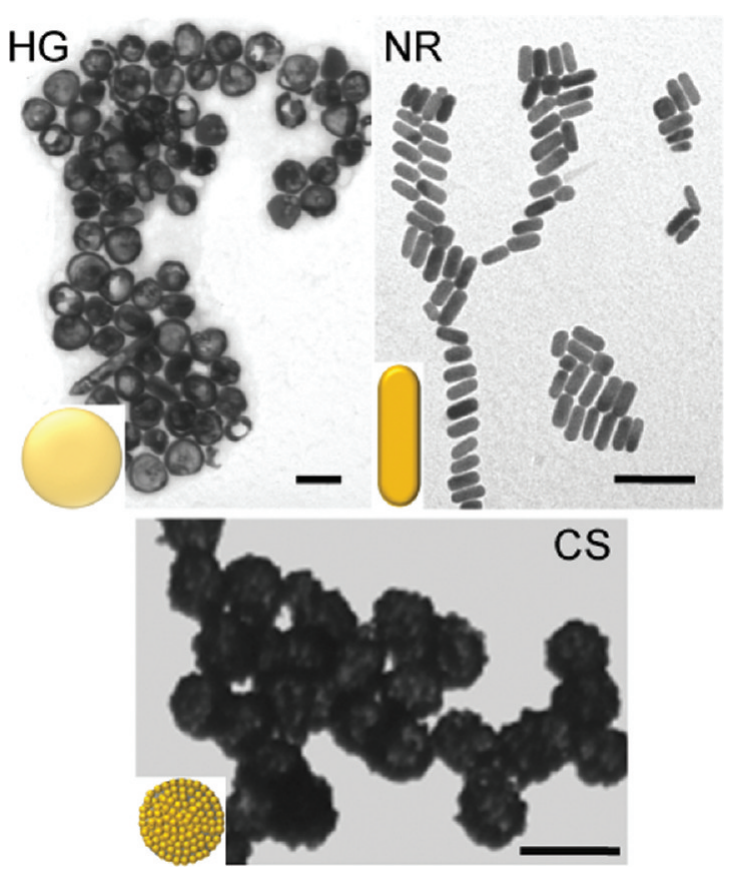

Figure 1. TEM images of nanoparticles used in the laser treatment experiments: hollow gold (HG), gold nanorods (NR), and silica/gold core-shell (CS). Scale bars represent $100 \mathrm{~nm}$.

influence of nanoparticle morphology in the laser-induced treatment, we used three different types of nanoparticles: gold nanorods (NR), gold hollow spheres (HG), and core/shell silica/gold spheres (CS) (see Figure 1). The nanoparticle morphologies were optimized to yield plasmon absorption bands in the near-IR region where the light can penetrate both blood and soft tissues (Figure 2). ${ }^{10}$ The particles were coated with monocarboxy(1-mercaptoundec-11-yl) hexa(ethylene glycol) (OEG), in order to introduce a terminal carboxylic group that has been shown to react with amine-terminated peptides, using standard coupling chemistry. ${ }^{11}$ Targeted attachment of the particles to the cellular membrane of human umbilical vein endothelial cells (HUVECs) was achieved by functionalizing them with the KPQPRPLS peptide (pep). We have recently demonstrated that nanoparticles functionalized with this peptide preferentially bind to the vascular endothelial growth factor receptors (VEGFR-1). ${ }^{12}$

The nanoparticles were characterized using several techniques such as transmission electron microscopy, dynamic light scattering, zeta potential measurements, and visible spectroscopy (see Figures 1 and 2 and Supporting Information).

A series of experiments were performed where functionalized (pep-OEG-HG, pep-OEG-NR, pep-OEG-CS) and nonfunctionalized (OEG-HG, OEG-NR, OEG-CS) particles were incubated with the endothelial cells and subsequently exposed to a range of laser power densities. Consistent with our previous work, ${ }^{12}$ the functionalized particles were mostly bound to the cellular membrane while the nonfunctionalized were internalized and confined in endosomes (see Supporting Information for TEM images of cross-sectioned samples). As illumination source for the laser-induced treatment, we used light from a supercontinuum fiber source (Fianium, 4 ps pulse length, $40 \mathrm{MHz}$ repetition rate), which was filtered to a spectral range of 680$720 \mathrm{~nm}$ using a bandpass filter. The laser power was varied between 0.75 and $5 \mathrm{~mW}$ yielding optical intensities in the cell

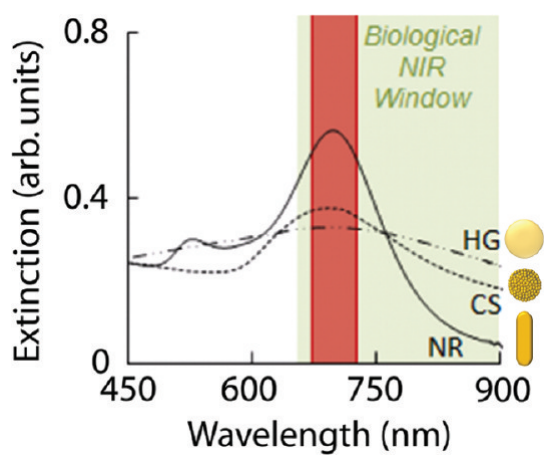

Figure 2. Optical extinction spectra of nanoparticles used in hyperthermia experiments. Nanoparticle shape and size are optimized for NIR illumination with the laser excitation band at $700 \pm 20 \mathrm{~nm}$ (red area).

culture between 5 and $32 \mathrm{~W} / \mathrm{cm}^{2}$ over a spot of $200 \mu \mathrm{m}$ diameter. A homogeneous, top-hat illumination profile was achieved by direct imaging of the output from a multimode fiber onto the cell culture. The exposure times were fixed to a value of $10 \mathrm{~min}$ for all experiments. Following laser irradiation, cells were incubated for either 1 or $24 \mathrm{~h}$ before staining the samples.

Figure 3 shows phase contrast images of cells incubated with peptide-functionalized particles before and $1 \mathrm{~h}$ after illumination at a laser intensity of $24 \mathrm{~W} / \mathrm{cm}^{2}$. The cells incubated with pepOEG NPs show clear changes in morphology, while this is not observed in cells incubated in the absence of nanoparticles (control sample in Figure 3). Before treatment, the HUVECs form a continuous layer displaying the typical cobblestone pattern. After treatment, this pattern is strongly disrupted and the cells show a detached morphology. A fraction of the cells also exhibits a pronounced shape change and shrinkage (see insets of Figure $3 b$ ). The effects of laser-induced treatment were further investigated by staining of the cells with Trypan Blue. Trypan Blue is a dye which is excluded from live cells but passes into the cytoplasm of cells exhibiting increased cell membrane permeability. Presence of the dye inside cells is therefore an indicator for cellular membrane rupture. As shown in Figure 3c, the number of cells with ruptured membrane is larger in the case of cells incubated with nanoparticles than in the control experiment. Between different types of nanoparticles, the hollow-gold and nanorod samples show a larger membrane rupture effect than the core-shell sample.

To better understand these results and to monitor the experimental conditions related to cell damage, we expanded our study, treating several cell-nanoparticle samples with different laser power densities ranging from 5 to $32 \mathrm{~W} / \mathrm{cm}^{2}$. Figure 4 shows graphs of the six different cell samples containing functionalized or nonfunctionalized particles and treated with various laser intensities. The damage of the cellular membrane for the different samples was monitored 1 and $24 \mathrm{~h}$ after laser treatment. For all samples, an increase of the intensity resulted in an increase in the percentage of the damaged cells. In the absence of nanoparticles, a significant increase in the number of damaged cells appeared only after exposure at the highest laser intensity used ( $32 \mathrm{~W} / \mathrm{cm}^{2}$, see Supporting Information). These observations highlight, first, the resistance of endothelial cells in temperature variations in comparison to other types of cells (such as tumors) $)^{13}$ and, second, the increase of ruptured cellular membranes when nanoparticles are associated with the cells during the laser treatment. 
a
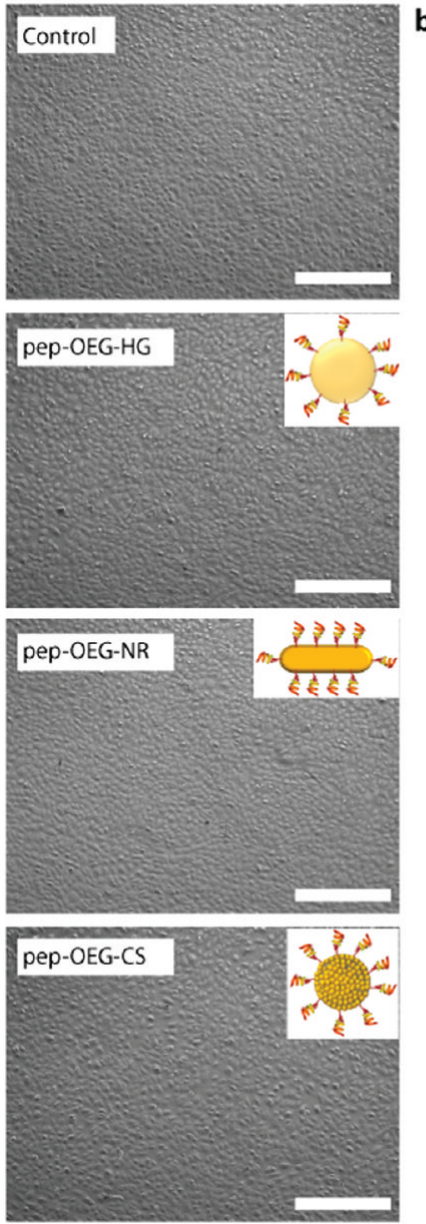
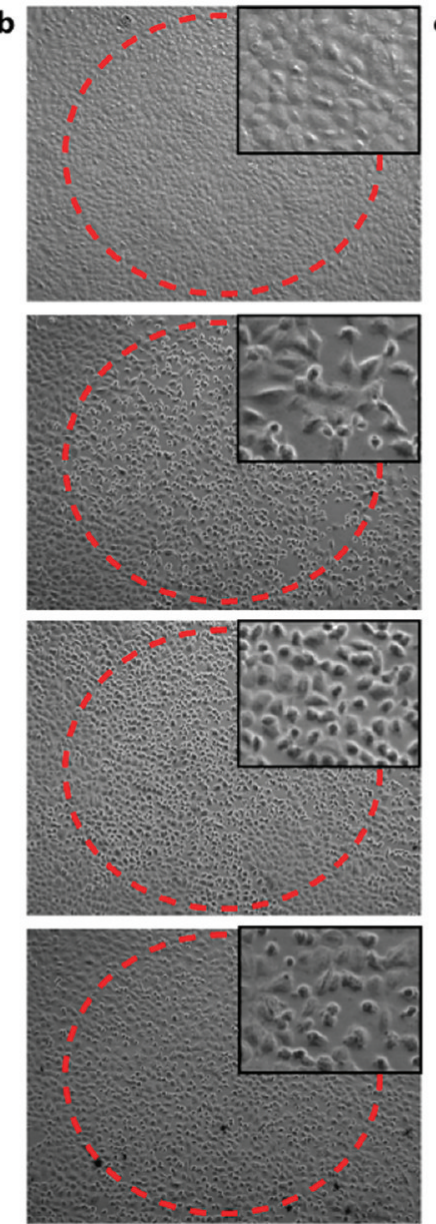
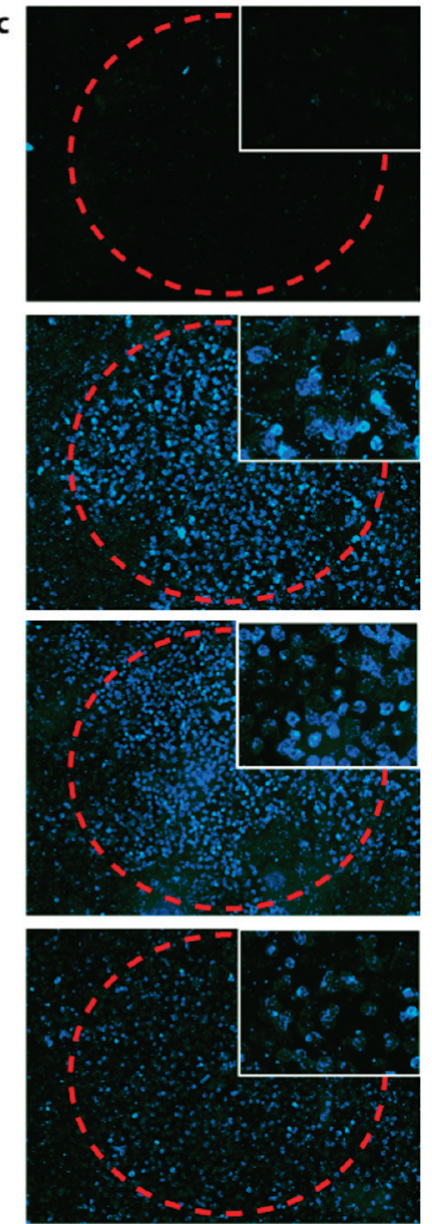

Figure 3. Phase contrast images of HUVECs before (a) and after (b, c) exposure to NIR laser $\left(10 \mathrm{~min}, 24 \mathrm{~W} / \mathrm{cm}^{2}\right)$ and $1 \mathrm{~h}$ incubation at $37^{\circ} \mathrm{C}$ followed by Trypan Blue viability staining (c). Rows represent HUVECs without particles (control) and KPQPRPLS-peptide functionalized hollow gold (pepOEG-HG), nanorods (pep-OEG-NR), and core-shell (pep-OEG-CS). Dashed circles represent laser spots. Scale bars represent $50 \mu \mathrm{m}$. Insets: detailed parts of main figures showing local cell distribution and morphology.

Pronounced differences in the damage of the cells are observed in Figure 4 between samples containing different kinds of particles. For all the experiments, the greatest number of ruptured cellular membranes (larger number of dyed cells) was always observed for samples containing nanorods and hollow gold particles, confirming that these types of particles had a dominant role on the cell damage.

The most striking observation in Figure 4 is that for the pepOEG-NPs samples, a large fraction of the cells showed a recovery $24 \mathrm{~h}$ after the laser treatment, as indicated by the area II (blue). The recovery is indicated by the absence of Trypan Blue from the cytoplasm, which translates to the cells having an intact cellular membrane. The repair of the cellular membrane reaches over $40 \%$ for pep-OEG-HG and pep-OEG-NR and around $30 \%$ in the case of pep-OEG-CS. Such cell recovery is not (or only mildly) observed for the cells incubated with OEGNPs (Figure $4 \mathrm{~d}-\mathrm{f}$ ). The reasons for these large differences in cell damage between samples containing functional and nonfunctional particles can be attributed to the way that the particles interact with each cell. ${ }^{12}$ The functional particles (pep-OEG NPs) interact specifically with the VEGFR-1 receptors and they are rarely taken up by the cells. Therefore the laser-induced treatment causes damage mainly to the membrane of the cell, which can be naturally repaired over time. This temporary membrane permeability has been shown in cells following shock treatments such as pulsed electromagnetic fields and osmotic stress ${ }^{14}$ and suggests a similar phenomenon following laser irradiation. On the other hand, the nonfunctional particles (OEG-NPs) are internalized and they are mostly found confined within the endosomes, causing critical damage not only at the cellular membrane but also at the subcellular level leading to cell death.

The results of Figure 4 indicate a strong influence of the presence and functionality of nanoparticles on the laser-induced damage and recovery of HUVECs. To further assess the influence of the treatment on cellular functions, we monitored the expression levels of two specific marker genes following exposure to laser irradiation. The marker genes selected here are indicators of endothelial activation, encoding the endothelial adhesion molecule 1 (ELAM-1) and the intercellular adhesion molecule 1 (ICAM-1). These genes play a critical role in angiogenesis and inflammation allowing the formation of new blood vessels and the recruitment of endothelial progenitors and inflammatory cells. ${ }^{15} \mathrm{~A}$ characteristic of these genes is that their expression is sensitive to stress imposed by variations to the cell surrounding environment (i.e., temperature changes). ${ }^{16}$ For the gene expression experiments, cell cultures were treated for $10 \mathrm{~min}$ at a laser intensity of 12 or $24 \mathrm{~W} / \mathrm{cm}^{2}$, followed by $1 \mathrm{~h}$ of 

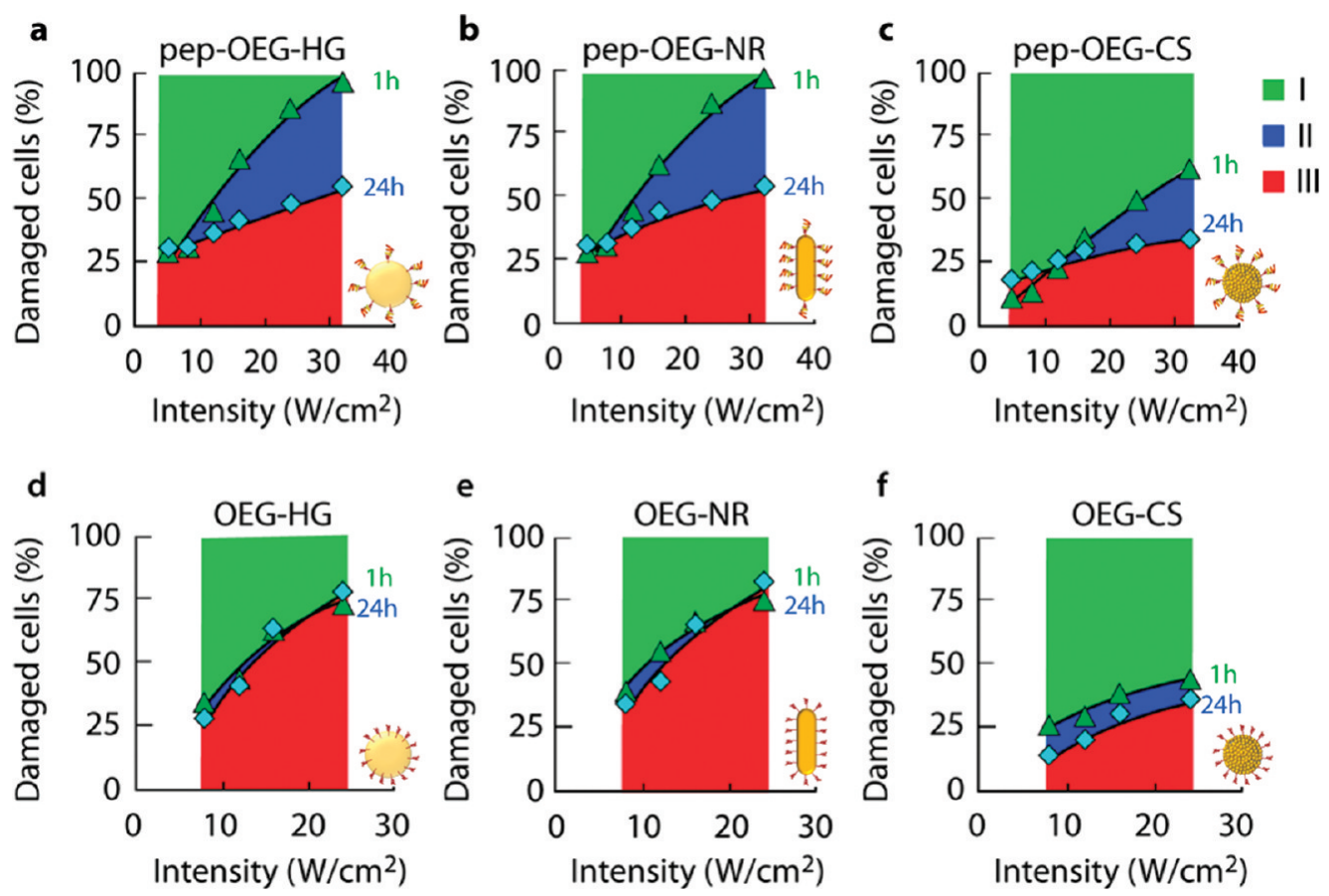

Figure 4. Cell viability for NP hyperthermia of HUVECs at various laser power densities, using hollow gold (HG) (a, d), rodlike (NR) (b,e), and coreshell (CS) nanoparticles. Particles are attached to KPQPRPLS peptide $(a-c)$ or coated with monocarboxy (1-mercaptoundec-11-yl) hexa(ethylene glycol) (OEG) (d-f). Symbols indicate percentage of dead cells determined after $1 \mathrm{~h}$ (triangles) and $24 \mathrm{~h}$ (diamonds) of incubation, which followed the exposure to the laser light. Numbered areas indicate (I) undamaged cells (green), (II) recovered cells after membrane rupture (blue), and (III) damaged cells (red).

rest, and then stimulated for $5 \mathrm{~h}$ with TNF- $\alpha$. Four different spots were exposed for each sample in order to achieve a large fraction of treated cells in the gene expression experiment. More information on the experimental protocols is available in the Supporting Information.

The resultant gene profiles are shown in Figure 5. The graphs indicate that in the presence of nanoparticles, both the ELAM-1 and ICAM-1 genes are significantly $(p<0.05)$ down-regulated, with a dependence on laser power. Overall, the hollow spheres and nanorods show a stronger effect on gene down-regulation in comparison to the core-shell particles. Control experiments in the absence of nanoparticles did not show any significant change in gene profile, indicating an absence of stress response at these laser intensities.

By comparing the gene expression and cell viability results, we identify a number of remarkable trends. First, the gene expression of the peptide-functionalized particles in Figure $5 \mathrm{a}$ at $12 \mathrm{~W} / \mathrm{cm}^{2}$ is much smaller than that in the rest of the graphs. In particular the comparison with OEG-type particles at the same laser intensity is remarkable since both types of particles in panels a and d of Figure 4 show a similar cell viability of around $35 \%$ at this intensity. Thus, for the same survival rate, the effect of laser illumination on gene expression is much smaller for nanoparticles attached to the cell membrane.

On the other hand, at $24 \mathrm{~W} / \mathrm{cm}^{2}$, a large gene down-regulation is observed for both the peptide and OEG-type particles (Figure $5 b, d$ ). Since gene expression profiling includes all cells that survived the laser treatment, the data in Figure 5b include a significant number of cells from recovered cells (type II in Figure 4), i.e., that have undergone a membrane rupture and repair event. Clearly, from the gene expression profiles there is no indication that these cells have reached a higher stress level than the OEG-type of particles.

We point out that even at the lowest laser intensities of this study, a sizable fraction of cells (25\% for hollow-gold and rods, $10 \%$ for core - shell) did not survive the laser treatment. This suggests the presence of additional, nonthermal mechanisms of cell damage, ${ }^{9}$ which will be addressed in future studies. Such investigations may include effects of pulsed versus continuous illumination, and of local variations in particle distribution in the cellular microenvironment and subcellular compartmentalization. ${ }^{17}$

In conclusion, we have investigated a range of intensities in which laser treatment of cells in the presence of plasmonic nanoparticles is used to control the cellular response. Pronounced differences are found between the laser-induced effects caused by OEG-type particles that are internalized into the endosomes and by peptide-coated nanoparticles which specifically target receptors present in the cellular membrane. A window of laser intensities is found in which the peptidecoated particles induce a recoverable rupture of the cellular membrane. Our results indicate that the possible applications of laser-induced plasmonic effects on noncancerous cells include the regulation of gene expression by application of external stress and modulation of the permeability of cellular membranes.

The use of HUVECs in our studies enables opportunities in both imaging and therapeutics where the control of vascular proliferation is a goal. Endothelial proliferation, especially in tumors, can lead to increased risk of metastasis and a poorer prognosis. Future research may be directed toward the control of more complex cellular organization processes, such as angiogenesis, using plasmonically targeted laser treatment. 

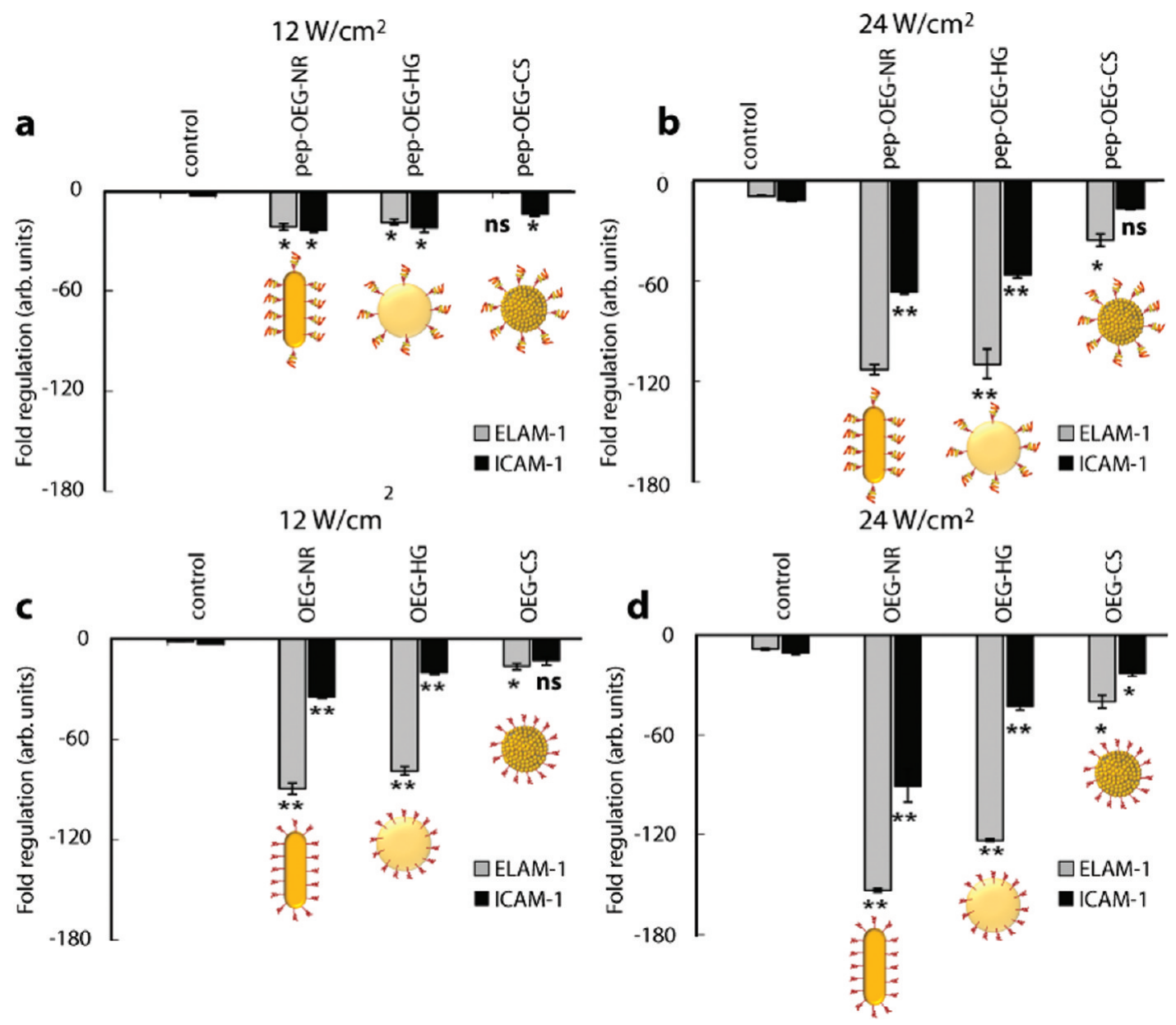

Figure 5. Gene expression profiling of HUVECs treated with KPQPRPLS peptide-coated NP (a, b) and to OEG-coated NP (c, d) after exposition to the laser light at power densities of $12 \mathrm{~W} / \mathrm{cm}^{2}(\mathrm{a}, \mathrm{c})$ and $24 \mathrm{~W} / \mathrm{cm}^{2}(\mathrm{~b}, \mathrm{~d})$ for $10 \mathrm{~min}$. Control samples did not contain any NP. All results are normalized relative to GAPDH expression levels and referred to nontreated HUVECs: ${ }^{*} p \leq 0.05$, ${ }^{* *} p \leq 0.01$, ns nonsignificant.

\section{ASSOCIATED CONTENT}

S Supporting Information. Further experimental details, characterization of nanoparticles, TEM images of crosssectioned cells, and additional gene expression profiles. This material is available free of charge via the Internet at http://pubs.acs.org.

\section{AUTHOR INFORMATION}

\section{Corresponding Author}

*E-mail: a.kanaras@soton.ac.uk.

\section{ACKNOWLEDGMENT}

We thank A. Page and D. Johnston for their technical support. The University of Southampton (NanoUSRG and Adventure in Research Scheme) and the Royal Society are gratefully acknowledged for funding of this project. A.G.K. thanks the Research Council UK (RCUK) for a Roberts fellowship. D.B. thanks the School of Physics and Astronomy and EPSRC for financial support. O.L.M. is supported by HEFCE through a SEPnet lectureship.

\section{REFERENCES}

(1) (a) Taylor-Pashow, K. M. L.; Della-Rocca, J.; Huxford, R. C.; Lin, W. Chem. Commun. 2010, 46, 5832-5849. (b) Bartczak, D.; Kanaras,
A. G. Langmuir 2010, 26, 7072-7077. (c) Yong, K. T.; Roy, I.; Swihart, M. T.; Prasad, P. N. J. Mater. Chem. 2009, 19, 4655-4672. (d) Ashcroft, J. M.; Gu, W.; Zhang, T.; Hughes, S. M.; Hartman, K. B.; Hofmann, C.; Kanaras, A. G.; Kilcoyne, D. A.; Le Gros, M.; Yin, Y.; Alivisatos, A. P.; Larabell, C. A. Chem. Commun. 2008, 21, 2471-2473. (e) You, C. C.; Chompoosor, A.; Rotello, V. M. Nano Today 2007, 2, 34-43.

(2) (a) Giljohann, D. A.; Seferos, D. S.; Daniel, W. L.; Massich, M. D.; Patel, P. C.; Mirkin, C. A. Angew. Chem., Int. Ed. 2010, 49, 3280-3294. (b) Minelli, C.; Lowe, S. B.; Stevens, M. M. Small 2010, 6, 2336-2357. (c) Huang, X.; Neretina, S.; El-Sayed, M. A. Adv. Mater. 2009, 21, 4880-4910. (d) Boisselier, E.; Astruc, D. Chem. Soc. Rev. 2009, 38, 1759-1782. (e) Sperling, R. A.; Pilar Gil, P. R.; Zhang, F.; Zanella, M.; Parak, W. J. Chem. Soc. Rev. 2008, 37, 1896-1908.

(3) (a) Chen, H.; Shao, L.; Ming, T.; Sun, Z.; Zhao, C.; Yang, B.; Wang, J. Small 2010, 6, 2272-2280. (b) Chen, J.; Glaus, C.; Laforest, R.; Zhang, Q.; Yang, M.; Gidding, M.; Welch, M.; Xia, Y. Small 2010, 6, 811-817. (c) Kuo, W. S.; Chang, C. N.; Chang, Y. T.; Yang, M. H.; Chien, Y. H.; Chen, S. J.; Yeh, C. S. Angew. Chem., Int. Ed. 2010, 49, 2711-2715. (d) Kuo-Wei Hu, K. W.; Liu, T. M.; Chung, k. Y.; Huang, K. S.; Hsieh, C. T.; Sun, C. K.; Yeh, C. S. J. Am. Chem. Soc. 2009, 131, 14186-14187. (e) Hasan, W.; Stender, C. L.; Lee, M. H.; Nehl, C. L.; Lee, J.; Odom, T. W. Nano Lett. 2009, 9, 1555-1558. (f) Lal, S.; Clare, S. E.; Halas, N. J. Acc. Chem. Res. 2008, 41, 1842-1851. (g) Huff, T. B.; Tong, L.; Zhao, Y.; Hansen, M. N.; Cheng, J.-X.; Wei, A. Nanomedicine (London, U.K.) 2007, 2, 125-132. (h) Jain, P. K.; El-Sayed, I. H.; El-Sayed, M. A. Nano Today 2007, 2, 18-29. (i) O’Neal, D. P.; Hirsch, L. R.; Halas, N. J.; Payne, J. D.; West, J. L. Cancer Lett. 
2004, 209, 171-176. (j) Pitsillides, C. M.; Joe, E. K.; Wei, X.; Anderson, R. R.; Lin, C. P. Biophys. J. 2003, 84, 4023-4032.

(4) (a) Cobley, C. M.; Au, L.; Chen, J.; Xia, Y. Expert Opin. Drug Delivery 2010, 7, 577-587. (b) Yavuz, M. S.; Cheng, Y.; Chen, J.; Cobley, C. M.; Zhang, Q.; Rycenga, M.; Xie, J.; Kim, C.; Song, K. H.; Schwartz,

A. G.; Wang, L. V.; Xia, Y. Nat. Mater. 2009, 8, 935-939.

(5) Chen, C. C.; Lin, Y. P.; Wang, C. W.; Tzeng, H. C.; Wu, C. H.; Chen, Y. C.; Chen, C. P.; Chen, L. C.; Wu, Y. C. J. Am. Chem. Soc. 2006, 128, 3709-3715.

(6) Hauck, T. S.; Jennings, T. L.; Yatsenko, T.; Kumaradas, J. C.; Chan, W. C. W. Adv. Mater. 2008, 20, 3832-3838.

(7) (a) Richardson, H. H.; Carlson, M. T.; Tandler, P. J.; Hernandez, P.; Govorov, A. O. Nano Lett. 2009, 9, 1139-1146. (b) Cole, J. R.; Mirin, N. A.; Knight, M. W.; Goodrich, G. P.; Halas, N. J. J. Phys. Chem. C 2009, 113, 12090-12094. (c) Govorov, A. O.; Richardson, H. H. Nano Today 2007, 2, 30-38.

(8) Urban, A. S.; Fedoruk, M.; Horton, M. R.; Rädler, J. O.; Stefani, F. D.; Feldmann, J. Nano Lett. 2009, 9, 2903-2908.

(9) Kreptic, Z.; Nativo, P.; See, V.; Prior, I. A.; Brust, M.; Volk, M. Nano Lett. 2010, 10, 4549-4554.

(10) El-Sayed, I. H.; Huang, X.; El-Sayed, M. A. Nano Lett. 2005, 5, 829-834.

(11) (a) Kanaras, A. G.; Kamounah, F. S.; Schaumburg, K.; Kiely, C. J.; Brust, M. Chem. Commun 2002, 2294-2295. (b) Hermanson, G. T. Bioconjugate Techniques; Academic Press: London, U.K., 1996; pp 169.

(12) Bartczak, D.; Sanchez-Elsner, T.; Louafi, F.; Millar, T. M.; Kanaras, A. G. Small 2011, 7, 388-394.

(13) Huang, X.; El-Sayed, I. H.; Qian, W.; El-Sayed, M. A. J. Am. Chem. Soc. 2006, 128, 2115-2120.

(14) (a) Rebersek, M.; Faurie, C.; Kanduser, M.; Corovic, S.; Teissie, J.; Rols, M. P.; Miklavcic, D. Biomed. Eng. Online 2007, 6, 25.

(b) Chakrabarti, R.; Pfeiffer, N. E.; Wylie, D. E.; Schuster, S. M. J. Biol. Chem. 1989, 264, 8214-8221.

(15) (a) Kim, I.; Moon, S. O.; Park, S. K.; Koh, G. Y. Circ. Res. 2001, 89, 477-479. (b) Griffioen, A. W. Cancer Immunol. Immunother. 2008, $57,1553-1558$.

(16) (a) Sawaji, Y.; Sato, T.; Takeuchi, A.; Hirata, M.; Ito, A. Br. J. Cancer 2002, 86, 1597-1603. (b) Sonna, L. A.; Fujita, J.; Gaffin, S. L.; Lilly, C. M. J. Appl. Physiol. 2002, 92, 1725-1742. (c) Brand, K.; Lubbe, A. S.; Justus, D. J. Int. J. Hyperthermia 1996, 12, 527-538. (d) Nakabe, N.; Kokura, S.; Shimozawa, M.; Katada, K.; Sakamoto, N.; Ishikawa, T.; Handa, O.; Takagi, T.; Naito, Y.; Yoshida, N.; Yoshikawa, T. Int. J. Hyperthermia 2007, 23, 217-224.

(17) Vogel, A.; Noack, J.; Huttman, G.; Paltauf, G. Appl. Phys. B: Laser Opt. 2005, 81, 1015-1047. 